\title{
Jacques Derrida'da Yazı ve Anlam Oyunu
}

\author{
Arş. Gör. Esra Başak Aydınalp \\ Anadolu Üniversitesi Ĕ̆itim Fakültesi \\ Fransız Dili Ĕ̆itimi Bölümü \\ esrabasakaydinalp@gmail.com
}

Öz

Yirminci yüzyılın ikinci yarısı, yazı üzerine sorgulamaların başladığı, yazı üzerine yazının; eleştirinin merkezine oturduğu bir döneme işaret eder. Bu sorgulamalar özünde yazının ne olduğuna değil, nasıl çalıştığına dair bir izlekten köken alır. Yazı üzerine yoğunlaşan eleştirel yaklaşım metnin kendisini nasıl oluşturduğuna yoğunlaşırken, Ferdinand de Saussure ve yapısalcılıkla başlayıp 1960'lı yıllara kadar süregelen göstergenin merkezde olduğu bir merkezileştirme çabası kendisini Jacques Derrida'nın deyimi ile yapının yapısallığı oyununa bırakır. Bu oyun kendini tüm anlam odaklarında yinelerken farklılaştırır, çoğaltır, dağııır, ayırır ve gösterge yerini ize bırakır. Bu iz, aynı zamanda sözmerkezci Batı düşüncesinin bütünüyle temellerinden sarsılarak sorgulanmasını ve yerini bir yapı söküm uğraşına bırakmasını, logosun içine hapsedilmiş tüm anlamsal ve yapısal çelişkilerin maskesinin düşürülmesini sağlayarak; orada ve şimdi mevcut olanı ertelenmiş bir "ayırama"1 tabi tutarak metnin dışında ve içindeki yapıları bir hareket içine dahil etmektedir. Bu dinamizm yazının iki anını imler. Öncelikle bir ters-yüz etme, bunu takiben bir yeniden kayda geçme anı yazının tüm anlamsal duraklarındaki çelişkileri ve hiyerarşik yapıları yapı söküme tabi tutar. $\mathrm{Bu}$ an, aynı zamanda bir okuma olayı ve anıdır. Yazı, okumanın vuku bulduğu bir tarihsel oluşa, bir eylem alanına dönüşür. Bu çalışmada, yazının Derrida'nın deyimiyle gramatolojinin (yazı bilimi) nasıl işlediği, yapı sökümün uygulandığı temel metinleri ve Derrida'nın "Yazıbilime Dair"(1967) ve "Yazı ve Fark"(1967) adlı eserlerinde ortaya koyduğu bu yapı söküm hareketi detaylıca incelenecektir.

Anahtar Kelimeler: Jacques Derrida, yazıbilimi, ayıram, yazı, yapı söküm.

\section{The Play of Writing and Signification in Jacques Derrida}

\section{Abstract}

The second half of the twentieth century indicates a period during which started the questioning of the critical and literary theory and the centralisation of the critic and the writing on the writing process. This questioning stems from a path on how the writing works, not on what the writing is fundamentally. The critical approach concentrating on how the text forms itself, starting from Saussure's structuralism until 1960s which is a try of

1 Ayıram, Derrida'nın Différance kavramının Türkçesidir. Sözcükteki "a” yazının söz karşılığında dinamik hareketini yansıtır. Şimdiki zaman ile geçmiş zaman arasındaki temsil etme ve var olmayı belirleyen diferans Fransızca' da aynı zamanda erteleme ve naklen olmadan verme anlamı da taşımaktadır (Akay 1999: 15). 
the centralisation of the sign leaves itself to a play of the structurality of the structure. This play whereas reiterates itself in all signification focuses, diversifies, reproduces, separates and disseminates and the sign turns to be the trace. This trace leads the structures outside and inside of the text into a movement subjecting which is actually there to a differance of deferral by ensuring the unmasking of all semantic and structural contradictions confined into the "logos" by questioning the totality and rocking to its foundations the thought of Western logocentrism and by erasing on-going metaphysics of presence giving way to a deconstruction. This movement bring along not only a deconstruction but also a reconstruction. This dynamism marks the two moments of the writing. First of all a procedure of eversion and a moment of re-inscription deconstruct all semantic contradictions, illusions, structures depending on the metaphysics of presence. This moment is also a moment and an event of lecture, the writing turns to be a field of action and a historical being in which the lecture happens. In this research, the movement of the deconstruction existing in the principal texts of Derrida entitled "Of Grammatology" (1967) and "Writing and Difference" (1967) and how grammatology works will be deeply examined.

Keywords: Jacques Derrida, grammatology, differance, writing, deconstruction. 


\section{GİRIŞ}

"Kavram, yazı onu ele geçirdiği anda olgunlaşır." Jacques Derrida

Yapısalcılık ve onu takiben post-yapısalcılığın hakim olduğu süreç, Aydınlanma sonrası özneyi merkeze alan şüpheci ve eleştirel yaklaşımlardan bir kopuşla birlikte dilin ve yapının yeni bir merkeze oturduğu anlamlı bir eğilimin doruğa çıktığı andır. Bu eğilim bir yanıyla Hegel diyalektiğini, öte yandan Sartre'ın varoluş ve Husserl'in fenomenoloji felsefesinin sorgulandı̆̆ı bir mecrada vuku bulur. Özne ve aklın hüküm sürdüğü Descartes felsefesi, Nietzsche'nin kendi yazısının $\operatorname{logos}^{\prime} a^{2}$ ve gerçeğe tabi olmadı̆̆ını söylemesiyle altüst olur (Derrida 1967: 32). Akıl, ve özne bir bütün olarak dünyayı olanaklı kılan öznellik olarak, birlik verici merkezi konumundan edilmektedir. Altuğ’a göre “özne dünya(sı) içerisindeki sarsılmaz konumunu kaybettiğine, bir anda konumsuz bir konuma geldiğine tanık olur" (2013, 215). Fransız felsefesi Heidegger'in etkisi altındadır. Nitekim Heidegger 1947'de kaleme aldığı "Hümanizm Üzerine Mektuplarında" Sartre'ın Varoluşçu hümanizmi ile arasına bir mesafe koyar ve dilin insanın sığınağı olduğunu ileri sürer.

Dilin öznenin ve aklın (logos'un) hakimiyetini sorgulattı̆̆ bu zemin önceleri yapısalcılıkla Ferdinand de Saussure'ün "Genel Dilbilim Dersleri" (1916) adlı eserinde dilin bir dizgeler sistemi olduğunu iddia etmesi ile, daha sonra Roland Barthes'ın göstergebilimi temel alan çalışmaları (Yazının Sıfır Derecesi (1953), Metnin Hazzı (1973)) ve bunu takiben Derrida'nın yapı söküm yaklaşımıyla dilden yazıya doğru yol alır. Bu çalışmada bu yolculuğun ana hatları belirlendikten sonra Derrida'da yazı kavramı söz merkezciliğin ve batı felsefesinde öteden beri var olan mevcudiyet metafiziğinin bir eleştirisi ile gramatoloji ve yapı-sökümün tüm temel bileşenleri analiz edilecektir. Derrida'nın söylemde dil, gösterge ve yapının oyununu analiz ettiği iz, ayıram, arkeyazı vs. gibi kavramlar netleştirilecektir. Böylelikle Derrida'yı felsefe'den edebiyata çağıran ve söz-merkezciliğin ölümünü müjdeleyen çanın (Glas, (1974)) ${ }^{3}$ sesi bütün çalışma boyunca yankı bulacaktır. Yazının eleştirel dinamiğinden yola çıkılarak Derrida'da yazı ve anlam oyunu derinlemesine analiz edilecek ve felsefe ve edebiyat kutuplaşmasında ikili hiyerarşinin yapı-söküme uğratılması için gerekli bir zeminin olanakları aranacaktır.

\section{JACQUES DERRIDA'DA YAZI KAVRAMI}

Cevizci'ye göre, yapısalcılıkta bütün sosyal fenomenleri dilbilimsel sistemler olarak görme yönünde bir gayret ve buna paralel olarak söz konusu sistemlerin eşzamanlı yapısını, bilimsel bir sistemi model alarak ortaya çıkarma eğilimi söz konusuydu. Oysa postyapısalcılıkta genel olarak sistematik düşüncenin doğasını, tarihsel açıdan daha duyarlı bir çaba içinde, edebi düşüncenin her daim yeniden yorumlayıcı gözlükleriyle ele alma eğilimi baskın çıkar. Bu eğilimin en belirgin biçimde görüldüğü kişi Jacques Derrida'dır (2012: 1243). Bu eğilim ile, 1967 yılında ele aldı̆̆ 1 "Yazıbilime Dair", "Konuşma ve Görüngü", "Yazı ve

\footnotetext{
2 Batı metafiziğinin temel olarak "Logos" metafiziği olması şu anlamlara gelir:

-Birinci anlamı "demek" fiilinden geliyor. Yunancası legein olan demek fiilinden türetilmiş olan bir isimdir logos. Bir yerde deme ya da deyiş diyebiliriz Türkçede.

-Legein' in diğer bir anlamı da "derlemek, toparlamak, bir araya getirmek"tir.

-Logos'un bir başka anlamı da dökümünü yapma, ayrıntılarını çıkarmadır. Bu farklı anlamları incelemek için Heidegger' in logosu konu edinen makalesine bakılabilir (Başer 2012: 386).

3 "Glas", Jacques Derrida'nın 1974 yılında yayınlanmış, metnin katı yönlerini yerinden oynatan; sağ sütunda Hegel'in "Salt Tin" kavramını, sol sütunda Jean Genet'in metnini yapı-söküme uğratarak söz-merkezci bakışın yapı-söküme uğratıldığ 1 edebiyat ve felsefenin buluştuğu eseridir.
} 
Fark" adlı eserlerinde Jacques Derrida; görüngübilime (Husserl), dilbilime (Saussure), (Lacanc1) psikanalize, yapısalcılığa (Lévi-Strauss) yöneltilmiş felsefi kabullerin en temel metinlerini eleştirel bir incelemeye tabi tutar (Sarup 2010: 53). Bununla da kalmaz, Jean Jacques Rousseau'yu yazıyı baskı altına almakla, onu sözün bir kopyası konumuna indirgemekle suçlar.

Heidegger'den sonra Derrida Fransız felsefesi ile ilgilenmiş, Sartre ve Merleau Ponty'i tanımış, Gaston Bachelard'ın ve George Cagulheim'im bilginin teorisi çalışmaları Derrida'nın Husserl ve Rousseau ile ilgili araştırmalarını etkilemiş, George Bataille'ın sosyoloji, poetika, felsefe üzerine, Michel Foucault'nun düşüncenin tarihi ve yapısı, Emmanuel Levinas'ın görüngübilim, etik ve Maurice Blanchot'nun yazı ve edebiyat üzerine yazıları Derrida düşüncesinin oluşumunda son derece anlamlı bir yere sahip olmuştur (Stocker 2006: 14).

Derrida "Yazı Bilime Dair" adlı eserinde yazı kavramına 1şık tutar, bu bağlamda "différance"(ayıram), "trace"(iz), "archi-écriture"(kök-yazi) ve "gramme"(yazi) kavramlarından yola çıkarak yapısöküm adı verilen yeni bir kavram geliştirir. Derrida söz/yazı karşıtlı̆̆ında sözü önceleyen metafizik önermeleri yapısöküme uğratır. Çünkü Derrida açısından yazı tüm tarih ve tarihsel oluş alanını açar, bu nedenle dilin kaynağı ile yazının kaynağı hiçbir şekilde birbirinden ayrilmaz (Aydınalp 2014).

\section{SÖZ MERKEZCİLIKK VE SESMERKEZCILIIK}

Sözmerkezcilik, Derrida'nın deyimiyle "Logocentrisme" Logos'u merkez alan, yani Derrida'nın çoğunlukla mevcudiyetle ilişkilendirdiği bir kavramdır. Sözmerkezcilik (logocentrisme) dilin, kendi başına var olan, temel olarak, tasarlanan bir anlam düzenidüşünce, hakikat, mantık, dünya vb. - tarafından yönlendirildiği ve bu anlam düzenini yansıttığı /aktardığı inanışında temel bulur (Altuğ 2013: 231). Batı felsefesi yazıdan kuşku duyup "insan sesine" ağırlık vererek sesmerkezci (phonocentrisme) olmasının yanısıra sözmerkezcidir, bütün düşünce, dil ve deneyimimizin temeli işlevini görecek nihai bir "söz", mevcudiyet, öz hakikat veya gerçekliğin var olduğuna inanır (Eagleton 2011: 142). Bu görüş açısından sözcükler, konuşan kişinin zihninde önceden mevcut anlam saltlığına ancak bir ölçüde yaklaşabilen aracılardır. Dolayımsız olan sözün yazıya göre bir önceliği vardır. Söz konuşmayı aktarmayı umduğu şeye, insanı çok daha yakın kılar. Bu da sözün mevcudiyetin imkanına çok daha yakın olduğu anlamına gelir (Altuğ 2013: 232). Derrida, "Platon'un Eczanesi"(1968) adlı yazısında, yazı ile mitin akrabalığını, her ikisinin de logos'tan ayırt ederek ilan eder. Buna göre Platon'da logos, bir oğuldur, babasının mevcudiyeti (presence) olmadan kendisini yok edecektir. O, babası olmadan bir yazıdan ibarettir. Yani yazı, babasının yokluğuyla (absence) ilişkilidir. Başka bir deyişle söylev ya da söz olarak logos, yazıdan önce gelir. Batı felsefesi hemen hep söz üstüne yoğunlaşmış, sesin üstünlüğü konusunda 1srarcı olmuştur (Orman 2015: 68).

Derrida'ya göre yazı kavramı sadece Platon'dan Hegel'e değil, görünür sınırların dışında, Sokrates-öncesi düşünürlerden Heidegger'e kadarki bütün farklara karşın, genel olarak gerçeğin kökenini hep logos'a atfetmiş olan metafizik tarihi, gerçeğin tarihi; hep yazının aşağılanması ve "dolu" sözün dışına itilmesi olmuştur (1967: 12).

"Yazıbilime Dair"(1967) adlı eserinin başından itibaren Derrida yazı kavramını buyruğu altına almış olan etnik merkezcilik (ethnocentrisme) dikkat çeker ve batı metafiziğinin bir eleştirel pratiğine girişir. Derrida, yazının metafizik olarak kavramsallaştırılmasına söz merkezcilik adını verir (1967: 11). Derrida tarafından ortaya 
atılan bu tez sözün yazıya göre ayrıcalıklı bir konumda olması ve anlamı anında yakalaması ve tam da bu nedenle mevcudiyete gönderme yapmasıdır. Derrida, batı düşüncesinin temelinde söz/yazı karşıtlığı olduğuna inanır. Bu karşıtlık ona göre batı felsefesini betimleyen bir dizi hiyerarşik karşıtlı̆̆ın (varlık/yokluk, ruh/beden, özne/nesne, erkek/kadın, söz/yazı, gösteren/gösterilen vs.) temelini oluşturmaktadır.

\section{MEVCUDIYYT METAFİíĞİNIN ELEŞTİRISI}

Derrida, yirminci yüzyılın ikinci yarısını da içine alan süre zarfında, batı düşüncesi ve felsefesinin mercek altına alındığı tetikleyici bir "olay" olan yazıyı ele alan entelektüel bir figürdür. $\mathrm{O}$, batının mevcudiyet metafiziği ve felsefesi tarafından sürekli baskılanan yazıyı özellikle edebiyat ve edebi eleştiriyi "dolu" sözün dışına iten indirgenmiş ve gerçeğin ötüldüğü bir an, olay gibi düşünür. Felsefeyi edebiyat karşısında yapı söküm adını alan bir düşünsel ve edebi eleştiri yöntemi geliştirerek "Logos' $u$ " merkeze alan felsefeyi yerle bir eden karşıt ve ikili hiyerarşik yapıları ters yüz ederek Heidegger'in yapısızlaştırma (destructuration) ve Nietzsche'nin merkezsizleştirmesini (decentralization) takip ederek eleştirir.

Derrida, mevcudiyet metafiziğini sorgular, ona göre batı metafiziğinde yazı/söz, erkek/kadın, kültür/doğa, gösteren/gösterilen, varlık/yokluk vs. gibi ikili karş̧ıt kavramlar arası hiyerarşik bir şiddet söz konusudur ve bu kavramlardan ilkine daha fazla değer atfedilmiştir. İkinci kavram ise batı felsefe tarihi boyunca baskı altına alınmıştır. Burada önemli olan ilk etapta sonu gelmeyen yapı söküm, merkezsizleştirme ve "hareketli" bir yer değiştirme ile bu kavramları bir ters-yüz etme oyununa açmaktır. Derrida'cı yapı söküm erkek, tanrı, söz gibi anlamı merkeze alan tüm yapıya meydan okur ve Derrida bu kavramları marja taşıyarak siler (sous rature). Böylelikle mevcudiyet metafiziği mevcudiyete verilen bir ayrıcalıkla batı felsefesini hakimiyeti altına alır. Bu ikili karşıtlıkların her biri bir mevcudiyeti, yok oluşu yok sayarak ön plana alır. Mevcudiyet bir kesinliktir, bu nedenle tüm filozoflar mevcudiyeti ayrıcalıklı kılmıştır. Ancak Derrida bu bakış açısını "sosyal bilimlerde gösterge, dil ve yapının oyunu" adlı Baltimore (1966) konuşmasında metafiziğin tarihinin merkeze bir merkez bulma ve bu merkezlerin yerini sürekli değiştirme tarihi olarak okuyarak ve yapı söküm hareketiyle merkezi merkezsizleştirerek, mevcudiyet kavramını ve yapının yapısallığını yerinden eder.

\section{GRAMMATOLOJI VE YAPISÖKÜM}

Derrida'nın sorgulaması gramatoloji adını alan bir yazı biliminin ortaya çıkışı üzerine kuruludur. Derrida'nın temel eseri olan "Yazıbilime Dair" (1967) onun felsefe ve edebi eleştiriye en özgün katkısını oluşturur. Eser "Yazının Başlangıcı ve Kitabın Sonlanışı" adlı bir bölüm ile başlar. Yazıya dair adlı eserinde Derrida kendi kişisel yazı pratiğini geliştirerek, batı metafiziği tarafından her zaman talep edilen bir merkez fikrini yapı söküme uğratır. Bu ilk bölüm

- Harften önce yazı

- Doğa, kültür, yazı şeklinde ikiye ayrılır.

Derrida bu eserde Saussure, Aristo, Platon, Hegel, Jacopson, Nietzsche, Heidegger, Peirce, Hjemslev, Descartes,Leibniz, Lévi-Strauss ile Jean-Jacques Rousseau'nun eleştirisi ve derin bir okumasını yapar. Derrida'nın eleştirel okuması bu düşünürlerin hepsinde özellikle aynı metafizik yanlışın tekrarlandığını göstermeyi amaçlar. Bu yanlış yazıya boyun eğ(dir)me ve onu indirgeme şeklinde gelişmiştir.

SEFAD, 2017 (38): 151-160 
Gramatoloji yazının baskı altına alınması sorunu ile ilgilenir, çünkü Derrida'ya göre tarih boyunca söz ve gösterge sorununa, yazıya karşın bir öncelik verildiğine tanık olmaktayız. Derrida'da gramatoloji bir yazı bilimi olarak tanımlanır. Gramatoloji yazılı izlerin bilimidir. Yazı, harf ve kayıt batı düşünce geleneği tarafından ruhun, sözün, logos'un dışında olan bir unsur olarak görülmüştür. Daha genel olarak gramatoloji tüm metafiziksel varsayımları yapı söküme uğratır. Gramatoloji' de "gramme" Yunancada yazı anlamına gelir ve anlam sürecinin mevcudiyet olarak düşünülmesinin olanaksızlığını betimler, Derrida bu süreci bir ayırım ve iz oyunu olarak görür. Gramme (yazı) bir ayırım işine gönderme yapar. Bu oyuna göre hiçbir öğe kendinde var olamaz. Gramatoloji, yazı ve söz arası ilişkiyi ve tüm metafizik varsayımları yapı söküme uğratır (Aydınalp 2014: 42).

Derrida yapı söküm eylemi ile bu eserde rasyonel kavramsallı̆̆ın bir eleştirisini yaparak ikili hiyerarşik yapıları sorunsallaştırır. Söz konusu eserin önemli bir kısmını LéviStrauss'un "Hüzünlü Dönencelerini" (1955) Jean-Jacques Rousseau'nun "Dillerin Kökeni Üzerine Denemesini"(1780-1789) incelemeye almıştır. Derrida'ya göre bu iki düşünür yazının baskılanması konusunda hemfikirdir. İkisine göre de yazı, yabancılaşmayı ama aynı zamanda politik, dinsel bir baskıyı anımsatır. Gramatoloji'nin ilk kısmı da sözmerkezciliğe bir giriş niteliği taşır. İkinci kısmı Levi-Strauss'un ve Jean Jacques Rousseau'nun derinlemesine bir okuması ve eleştirisini içerir. Derrida'ya göre Levi-Strauss modern dünyaya yazının girişini bir şiddet eylemi olarak algılar ve yazıyı Rousseau'nun “iyi yabaninin" mutlu ve özgür doğasını sarsan bir unsur olarak görür. Yazının söze karşı bu indirgenişi bir söz merkezciliğe bağlıdır. Derrida bu durumu yapı söküm ile ters-yüz eder. Yapı söküm metni yok eden veya metne zarar veren bir işlem değildir, ancak yapı söküm metnin içindeki yapıların ikili bir seansta (double-seance) maskesini düşürmek için metnin içini oyar. Bu nedenle yapı söküm iki aşamada gerçekleşir.

1-Ters-yüz edilme: hiyerarşik olan ikili yapıda ki güç ilişkisi yok edilir. Bu ilk anda yazı söze, kadın erkeğe, öteki aynıya, yok oluş, mevcudiyete ayrıcalıklı kılınır.

2-Nötrleşme: İlk kısımdaki ikili yapıda öncelikli ve ayrıcalıklı kılınan kavram hiyerarşik güç ilişkisi dengesinden sökülüp, daha öncül olan ve ikili düşünce içerisine yerleşik bulunan anlamlar terk edilir. Bu faz bir üst-ses (super-voix), bir androjeni (androgénie) ve bir arkeyazının (archi-écriture) doğmasını sağlar. Yani ikili yapıdan sökülen kavram kararsızlaşır (indécidabilité) (Hottois 1998: 306).

Derrida'da yapı söküm bir anlam açılımı, sürekli ertelenen, kararsız ve dağılmış anlamın genişlemesine tabi olan yazı sorunsalına dair bitmez bir sorgulama ve dönüşüm hareketidir. Yazı söz merkezci düşüncenin yetim çocuğu olarak Derrida'da yazıbilime bağlı bir takım nosyonlar (iz, ayıram, dağılım) ile kendini konumlar. Yapı söküm bu ayıramın sürekli ertelenen anlam dahilinde izini sürer. Gösterilen yerini bu anlam zincirinde sürekli başka gösterilenlere bırakır. Gösterilenin yerinden edilmesi, göstergenin metafiziksel problematiğini oluşturan ikiliğin tersine çevrilmesi işlemi ile gerçekleşir (Altuğ 2013: 220). Bu işlem yapı sökümdür.

\section{JACQUES DERRIDA'DA DIL VE ANLAM OYUNU}

Genel olarak post-yapisalcilikta dil durumunu karakterize eden dilsel olgu, göstergenin yapısal statüsünün yerinden edilmesidir (Altuğ 2013: 216). Derrida, gösteren ile gösterilen arasındaki ayrımı silmenin iki yolu olduğunu düşünür: klasik yol göstereni düşünceye tabi kılmak, ikinci yol önceki indirgemenin işlevde bulunduğu dizgeyi soru konusu yapmaktan oluşur (Altuğ 2013: 220). Saussure'a göre, gösteren ile gösterilen 
arasındaki ilişki keyfidir. Kültürel ve tarihsel uzlaşımlarla gösteren gösterilene bağlanmıştır. Böylece sistemdeki her gösterge yalnızca diğerleriyle arasındaki fark sayesinde bir anlama sahip olur. Saussure'un bu düşüncelerinin temelinde dili, artzamanlı değil de, yani tarihsel gelişimi içinde değil, aksine eşzamanlı olarak, yani tarihin belirli bir noktasında bütün bir sistem olarak, yani bir dizge olarak ele alması ve yorumlaması gerçeği yatmaktadır (Eagleton 2011: 125-126). Derrida açısından ise, sözcük ile şey ya da düşünce gerçekte asla bir ve tek olamazlar. Aksine gösterenler ile gösterilenler sürekli olarak yeni birleşimler içinde ya birbirlerinden koparlar ya da bir araya gelirler. Başka bir deyişle, göstergeler, yokluğu gösterirler, dolayısıyla bir anlamda anlamları yoktur. Anlam sürekli olarak bir gösterilenler zinciri boyunca devinir ve asla onun kesin konumundan emin olamayız, çünkü anlam asla tek bir göstergeye bel bağlamaz (Sarup 2010: 40-41). Dil dizgesi, göstergenin metafizik hiyerarşisinden bağımsız kılma girişimi, Derrida'nın, "yapı" kavramı ve "yapının yapısallığına" ilişkin tartışmasında yakalanabilir. Bu çözme süreci yapısalcılığın yapıya verdiği anlam içerisinde "merkezin" yerine "oyunun" ikame edilmesi ile sonuçlanacaktır (Altuğ 2013: 221).

\section{IZ VE AYIRAM}

Fransız Felsefe Topluluğunun 1968 yılında düzenlenen konferansı sırasında Derrida ayıram (differance) kelimesini açıklamaya çalışır ve ona göre ayıram ne bir kelime ne bir kavramdır. Burada söz konusu olan yazı sorunsalı üzerine bir yazı sürecinde düşünülen bir müdahale tarzıdır. Bu yazılı farklılık yazıda yazılan ve okunulan ancak duyulmayan ve söylenemeyen bir " $\mathrm{A}$ " nin hareketi ve Derrida felsefesinin bir sentezidir. Bu sentez gösterilen ile göstereni biteviye bir zincirsel hareket dahiline sokar. Ayıram, eşzamanl, tarihsel olmayan, sınıflandırılabilen, durağan motiflere uygun değildir. Ayıram, Derrida tarafından söz merkezciliğe karşı Derrida tarafından üretilmiştir. Bu terim hem farklılaşmak, hem de ertelemek anlamlarına gelen "différer" fiilinden türetilmiştir. Derrida bu terimi yazı üzerine bir yazıyı düşünmenin olanaklarını ararken geliştirmiştir. Derrida, Saussure'cü dilsel dizge teorisini alarak bu teorinin yapı sökümcü bir tekrar okumasını yapar ve buradaki gösterge kavramı yerini iz ve ayıram terimlerine bırakır.

Yapı sökme eylemi çelişkileri göstermektir. Çelişkilerin arasındaki fark onto-teolojik bir fark değil, bir ayıram (différance) olacaktır. Şimdiki zaman ile geçmiş arasındaki temsil etme (ya da temsiliyet) ve var olma (ya da mevcudiyet) ilişkisi içinde yer alacaktır. Geçmişte olanı şimdiki zamanda var eden mevcut kılan eylem ayıramdır. Kendi içinde kapalı olan mekanı ve dışarıdan gelen mutlak dışarısılığı ve radikal bir ötekiliği içermektedir. İzin hem yerleşmesini hem de silinişini belirleyen, ekonomik bir harekettir. Ve zaten iz bir ektir (supplement) (Akay 1999: 16).

İz bir kökenin, anlam zinciri üzerinde sürekli ertelenen bir mevcut olmayan farklılaşan varlığın olanaksızlığıdır. " $\mathrm{A}$ " nın sonsuz hareketi bizi izin ve göstergenin sonsuz oyununa çağırır. Ayıram ve izler sisteminde farklılıklardan başka bir şey yoktur. Ayıram dolayısıyla aynı olmayan benzerlik ve bizi kendisiyle aynı ve kendisinden ayrı olan iz kavramına gönderir. Derrida'ya göre anlamın mevcudiyeti asla tamamlanamaz, bu düşünce rasyonalistler tarafından kolayca kabul edilmemektedir, çünkü her gösterge ya bir önceki ya da bir sonraki göstergeye gönderme yapar, böylelikle göstergenin kendi öz kimliği ve anlamın mevcudiyeti çözünür. Diğer bir deyişle anlam asla mevcut değildir, çünkü anlam sürekli referanslara bağlı bir bağlam dahilinde gelişir, bu bağlam belli değişimlere tabidir. Derrida bu değişimlere ayıram (différance) adını verir. Bu farklılıklar izin tanımlanması,

SEFAD, 2017 (38): 151-160 
kimlik bulması dilbilimsel göstergenin mevcut olmasını engelleyen işaretleridir. Böylelikle ayıram gösterilenlerin açık bir oyunu olarak düşünülebilir.

Yazıbilime dair adlı eserinde Derrida bir anlam sisteminde göstergenin sürekli öteki göstergelerle var olduğunu ve anlam bulduğunu, bir göstergenin asla kendinde var ve anlamlı olmadığını söyler. Bu sürekli ve sonsuz tekrar ve asla nihai anlama ulaşamama durumu onun yazıya dair vurgulamak istediği en temel yöndür.

\section{ARKEYAZI VE ITERABİLITE}

Biz yazıyı konuşmadan sonra gelen daha doğrusu tarihi tarih öncesinden sonra gelen bir durum olarak algılarız. Bunun sonucu olarak, Derrida, kendisine göre yazının "sonra" (sözden sonra, tarih öncesinden sonra) gelmeyip kökensel olduğunu, zaten her zaman mevcut olduğunu gözler önüne sermek için "Kök-yazı (archi-écriture)" ifadesini ileri sürer (Ramond 2011: 21). Bu durumda Derrida aslında alıcı/muhatap yokluğu (iletişimde) her durumda yazıdakiyle aynı rolü oynadığı için her iletişim biçiminin esas itibariyle "yazı" olduğunu savunarak, geçerli (felsefi, gerçekteyse "metafizik") yazı anlayışını büsbütün alaşağı etmek üzere, yazıda alıcının zorunlu yokluğuna dayanacaktır (aslında, tanımı gereği, ancak olmayan birine (bir yokluğa) yazılabilir). Gerçekte, alıcının olmadığı bu iletişim şekline "yazı" demeyi tercih edersek, Derrida'nın savı, aslında her iletişim biçiminde, hatta ortak-mevcudiyet görünüşünde bile daima zorunlu olarak "yazı" (ya da yokluk) olduğunu savunmaktan (ya da saptamaktan) ibarettir. Netice itibariyle her iletişim modeli ona göre yoklukta iletişimdir, yani böylece paradoksal olarak sözlü iletişimin dayanacağı yazıdır (Ramond 2011: 23). Derrida'ya göre sadece tek bir yazı yoktur, fakat iki tane yazı, iki tane metin vardır. Fonetik yazı sese, söz, logosa eklemlenir. Oysa yazı yani arkeyazı ayıramı temel alır ve söz merkezcilik ve ses merkezciliği yerinden eder, bir fark yaratır. İkisi arasında bir uzlaşı, bir diyalektik ilişki yoktur. Halbuki iki metinde aynı kökene dayanır. Alfabetik yazı dilin içsel gereksinimlerine cevap verir. Otorite sahibidir. Onunla hakikat dilsel kodlara, yasalara ve mantığa göre düzenlenir. $\mathrm{O}$, yani söz oğlu ve hiyerarşiyi yaratır, mekanı ve sosyal yaşamı organize eder. Kök-yazı ise anlamın kökeninden beri işler haldedir. Bu hiyerarşiyi kırar. Doğduğu andan itibaren yazı, yazarı tarafından terkedilmiştir. O artık yetimdir. Artık bir eklenti olabilir, o artık yinelenebilirdir. Derrida'ya göre yapısal olarak okunabilir-yinelenebilir- olmayacak bir yazı, yazı olmaz (Ramond 2011: 129).

\section{SONUÇ}

Bu çalışmada Derrida'nın yapı söküm uğraşının temel bileşenleri ele alınarak, betimlenmeye çalışılmıştır. Bu uğraşın bir sonucu olabileceği düşüncesi Derrida'nın temel düşünsel sistematiğine ters olmakla birlikte, yapılmak istenen Derrida'nın yazı bilimini açıklamak, bu bakış açısının metne yaklaşımını gözler önüne sererek metni ikili karşıtlıklar dizgesinin uyguladığı şiddetin dışına çıkarabilmek, diğer bir ifadeyle metni özgürleştirmektir. İki kelimeyle söylenecek olursa, Platon'dan beri, batı metafiziği kökeninden itibaren, yazının ve okumanın birlikte oluşu unutulmuş değil, fakat baskılanmıştır ve söz ile duyuş her zaman eril ve ataerkil bir durumla ilişkilendirilmiştir (Lisse 1998: 11). Bu nedenle öncelikle yazı ve okuma sözün hüküm sürdüğü kültürde özgür kılınmalıdır. İlk başta da ifade ettiğimiz gibi Derrida'ya göre kavram, yazı onu ele geçirdiği anda olgunlaşır. Yazı, batı metafiziğinde öteden beri süregelen şiddeti görünür kılar. Bu hiyerarşik, ötekileştiren, yayılmacı şiddetin çözündüğü an yapı söküm anıdır. Derrida'ya göre "Metnin dışında bir şey yoktur". Metinde anlam sürekli yinelenen ve ertelenen izlerin 
izdüşümüdür. Yapı söküm bir bozma, bir dağılma değil aksine bir yeniden oluşturma işlemidir. Bu yeniden oluşum, yine Derrida'nın tabiriyle iki yazılım anını, yapı sökümün ikili kaydını imler. Bu kayıt asla bir katı mevcudiyet anı değil, aksine kendinde varoluşun eleştiriye açıldığı andır. Batı metafiziği varoluşundan beri bu katı mevcudiyet anının kıskacındadır. Yapı söküm buna karşın bir nihilist teori, bir yok ediş değil, bir yeniden üretme, yazıyı yeniden okuma olayıdır. Bu olay yapının hareketini gözler önüne serer ve yapının yapısallığı, kendisini yapının (ayıram ve iz ile birlikte) bir anlam oyununa bırakır. Bu oyunun ne bir kökeni ne de bir sonu vardır. Bu oyun kendisini bir yapı söküm hareketi ile sürekli olarak yineler. Bu hareket anlamın oynak bir zeminde sürekli olarak ertelenmesi ve kendisini silmesi ile betimlenir.

\section{SUMMARY}

Deconstruction had a major influence as a literary criticism method on the last decades of twentieth century. Derrida, who was also under the influence of Friedrich Nietzsche and Martin Heidegger, questioned the role of the language, subject, sign etc. in his work entitled Of Grammatology and Writing and Difference published in 1967. He criticized binary thinking system of the Western thought originated from the attempt of attributing a centre for not only history as Derrida stated in his Baltimore Discourse in 1966 but also all forms of reflections of the Western thinking. This is called "Logos" and the way of such thinking leads Western thinkers to a logocentric approach. Derrida on the contrary claims that there is no transcendental signified, so the various traditionally subscribed ideas by the Western civilization are based on the metaphysics of presence which is also logocentric for Derrida and include the acceptance of a transcendental signified as ultimate source of knowledge. Our thinking according to deconstruction which is the method developed by Derrida to reread the Western civilization under the lens of dissemination, trace and differance by putting the transcendental signified under erasure, consists of the ongoing play of signifiers that never come to an end and move from one to another in a chain of signification. Even though, we try to achieve stability in the meaning of a text, we are directly caught by the language, which refuses to stay fixe. This play leads us to replace the sign by trace, which consists of rests of the play of signifiers. As a result the word signals what is deferred or differed. This ongoing play is called "differance" by Derrida which is originated from French words "to defer" and "to differ" proposing that the signification is always postponed. Differance asserts that knowledge stems from dissimilarity and absence making meaning dynamic and contextual. This dynamism prevents to grasp the meaning of any text in a glance. It marks the two moment of the writing. First of all a procedure of reversion and a moment of re-inscription deconstruct all semantic contradictions, illusions, the structures depending on the metaphysics of presence. This moment is also a moment and an event of lecture, the writing turns to be a field of action and a historical being in which the lecture happens. In this research, the movement of the deconstruction existing in the principal texts of Derrida entitled "Of Grammatology" and "Writing and Difference" and how grammatology works in words of Derrida will be deeply examined. The writing and signification play on the basis of the critical dynamic of writing in Derrida will be analysed and the possibilities of a required groundwork will be quest for deconstructing the dual hierarchy and polarization of Philosophy/Literature.

SEFAD, 2017 (38): 151-160 


\section{KAYNAKÇA}

AKAY, Ali (1999). Yapıbozma ve plastik sanatlar. Toplumbilim (10): 13-23.

ALTUĞ, Taylan (2013). Dile gelen felfese. İstanbul: Yapı Kredi Yay.

AYDINALP, Esra Başak (2014). Le concept d'écriture chez Jacques Derrida, une analyse thématique et descriptive. Yüksek Lisans Tezi. Eskişehir: Anadolu Üniversitesi.

BAŞER, Nami (2011). " Derrida: Husserl Fenomenolojisiyle Heidegger Ontolojisinden Farklı Bir Metafizik(ten) Çıkış ». Kant Sonrası Metafizik Üzerine Konuşmalar. Istanbul : Küre Yay.

CEVIZCİ, Ahmet (2012) Felsefe Tarihi. İstanbul: Say Yay.

DERRIDA, Jacques (1967). De la grammatologie. Paris: Les Éditions de Minuit.

DERRIDA, Jacques (1967). L'écriture et la différance. Paris: Éditions du Seuil.

EAGLETON, Terry (2011). Edebiyat kuramı. çev. Tuncay Birkan. İstanbul: Ayrıntı Yay.

FIRINCI ORMAN, Türkan (2015). "Jacques Derrida Düs,üncesinde "Dil". Kilikya Felsefe Dergisi (1): 61-81.

HOTTOIS, Gilbert (2005). De la Renaissance à la postmodernité, une histoire de la philosophie moderne et contemporaine, De Boeck, Bruxelles

LISSE, Michel (1998). L'expérience de la lecture, la soumission. Paris: Galilée

RAMOND, Charles (2011). Derrida Sözlüğü. çev. Ümit Edeş. İstanbul: Say Yay.

SARUP, Madan (2010). Postyapısalcılık ve postmodernizm.ç. A.Baki Güçlü. İstanbul: Kırk Gece Yay.

STOCKER, Barbara (2006). Derrida on deconstruction. Routledge Philosophy Guidebooks Taylor and Francis Group: Newyork and London. 